\title{
DESEMPENHO AGRONÔMICO E ECONÔMICO DE GENÓTIPOS DE MILHO EM SAFRINHA TARDIA NA REGIÃO SUDOESTE DA AMAZÔNIA
}

\author{
Alexandre Martins Abdão dos Passos ${ }^{1}$, Frederico José Evangelista Botelho ${ }^{2}$, Vicente \\ de Paulo Camps Godinho², Andréia Marcilane Aker ${ }^{3}$, Simone Marçal Quintino ${ }^{4}$ \\ 1. Pesquisador da Embrapa Milho e Sorgo, Sete Lagoas, MG, Brasil, \\ alexandre.abdao@embrapa.br \\ 2. Pesquisador da Embrapa Rondônia, Porto Velho, RO, Brasil \\ 3. Doutoranda em Produção Vegetal, Universidade Federal dos Vales do Jequitinhonha \\ e Mucuri - UFVJM, Diamantina, MG, Brasil \\ 4. Doutoranda em Desenvolvimento Regional e Meio Ambiente da Fundação \\ Universidade Federal de Rondônia - UNIR, Porto Velho, RO, Brasil
}

\section{Recebido em: 22/09/2018 - Aprovado em: 23/11/2018 - Publicado em: 03/12/2018} DOI: 10.18677/EnciBio_2018B32

\begin{abstract}
RESUMO
Com grande importância no Brasil, a cultura do milho ainda apresenta produtividade baixa, devido dentre outros fatores, à falta de cultivares adaptadas às regiões de cultivo emergentes. Desta forma, objetivou-se avaliar o desempenho agronômico e econômico de 16 genótipos de milho no período final de segunda safra no município de Porto Velho, Rondônia. O experimento foi realizado empregando-se 0 delineamento em blocos casualizados com quatro repetições. Foram avaliados a produtividade de grãos, alguns atributos agronômicos e o balanço econômico do uso dos genótipos. Observou-se produtividade média dos genótipos testados, inferior à média nacional. Os genótipos influenciaram todas as variáveis agronômicas avaliadas. Os genótipos 1F640 e IAC 8390 apresentaram as maiores médias de produtividade com $5.424 \mathrm{~kg} \cdot \mathrm{ha}^{-1}$ e $4.723 \mathrm{~kg} \cdot \mathrm{ha}^{-1}$, respectivamente. O híbrido de pipoca IAC 125 proporcionou a menor produtividade (1.785 kg.ha-1), contudo, destacou-se com a maior receita líquida obtida. No geral, os menores custos de produção foram obtidos pelo uso de variedades, enquanto as maiores receitas líquidas e relação benefício custo foram verificadas para os híbridos. Conclui-se que a adequada escolha do material genético utilizado na semeadura ao final da segunda safra é preponderante para a obtenção de apropriados níveis de produtividade de grãos e receita líquida.
\end{abstract}

PALAVRAS-CHAVE: interação genótipo-ambiente, segunda safra, Zea mays

\section{AGRONOMIC AND ECONOMIC PERFORMANCE OF MAIZE GENOTYPES UNDER LATE OFF-SEASON IN SOUTHWEST AMAZON REGION}

\begin{abstract}
Corn is an important crop in Brazil, however it presents low grain yield, due, among other factors, to the lack of adapted cultivars indication addressed to emerging growing regions. The aim of this paper was to evaluate the agronomic and economic performance of 16 maize genotypes during the second growing season. The experiment was carried out in Porto Velho, Rondonia using the randomized blocks
\end{abstract}


desing with four replicates. The following attributes were evaluated: plant height, ear insertion height, number of lodged and broken plants, number of sterile and diseased ears, length and diameter of ears, weight of one hundred grains and grain yield. The results showed an average productivity of the tested genotypes below the national average. The genotypes 1F640 and IAC 8390 presented the highest averages for the second growing season conditions $\left(5,424 \mathrm{~kg} \cdot \mathrm{ha}^{-1}\right.$ e $4,723 \mathrm{~kg} \cdot \mathrm{ha}^{-1}$ respectively. The popcorn hybrid, IAC 125 provided the lowest grain yield among genotypes (1,785 $\mathrm{kg} \cdot \mathrm{ha}^{-1}$ ), however it show the highest net revenue. In general, the lowest production costs were obtained by the use of varieties, while higher net revenue and benefit cost ratio were checked by hybrids use.

KEYWORDS: environment-genotype interactions, off-season crop, Zea mays

\section{INTRODUÇÃO}

Embora ainda pouco expressiva no contexto nacional, a produção de milho em Rondônia vem se expandindo de maneira significativa em semeaduras de segunda safra em sucessão à cultura da soja (CONAB, 2018). Assim, como em toda a região Norte, a produtividade média obtida com a cultura do milho no estado, ainda é considerada baixa quando comparada à de outras regiões do país, tanto para a safra principal quanto para a segunda safra. Esta baixa produtividade é relacionada a diversos fatores, dentre os quais se destaca a carência de oferta e uso de tecnologias apropriadas e indicação de cultivares adaptadas às condições locais (CARVALHO et al., 2013; SANTOS et al., 2018).

A semeadura da segunda safra (safrinha), apresenta-se como um cultivo de risco elevado devido à maior possibilidade de ocorrência de estiagens durante o desenvolvimento das plantas, que proporciona reflexos negativos sobre a produtividade de grãos (SOLER et al., 2007). Neste sentido, os produtores, têm optado tradicionalmente por alocar menor investimento nesta modalidade de cultivo de sequeiro, minimizando, desta forma, os riscos econômicos com o uso de sementes de menor custo e menor quantidade de fertilizantes (SILVA et al., 2015a; MONTEIRO et al., 2017). Nesse contexto, o controle de custos é essencial visando gerar suporte para tomadas de decisão e auxiliar no planejamento, gerenciamento e avaliação econômica das atividades (FALEIROS et al., 2018).

Em cultivos de alto e médio investimento com manejo e uso de insumos, as cultivares de polinização aberta têm promovido produtividades inferiores aos híbridos (SILVA, et al., 2015b; OLIVEIRA et al., 2017). Entretanto, a utilização de variedades, de menor custo de semente, pode ser economicamente vantajosa para semeadura em segunda safra. Enquanto que por outro lado, a utilização de milhos especiais, voltados para nichos de mercado, pode representar uma estratégia para obtenção de maior sustentabilidade econômica na atividade (SUZUKAWA et al., 2018).

Diante do exposto, o presente estudo teve como objetivo avaliar o desempenho agronômico e econômico de 16 genótipos de milho cultivados no período de segunda safra no Sudoeste da Amazônia.

\section{MATERIAL E MÉTODOS}

O experimento foi conduzido no campo experimental da Embrapa Rondônia, localizado no município de Porto Velho, na região Norte do estado de Rondônia, latitude 847'38,27" Sul, longitude 6350'48,26” W e $87 \mathrm{~m}$ de altitude. A classificação do clima (Köppen) é tropical úmido do tipo Am (BASTOS; DINIZ, 1982). O período de realização do experimento foi compreendido entre abril e junho de 2012. Os 
dados relativos à precipitação pluviométrica e temperaturas médias, registrados durante o período de condução do experimento são apresentados na Figura 1.

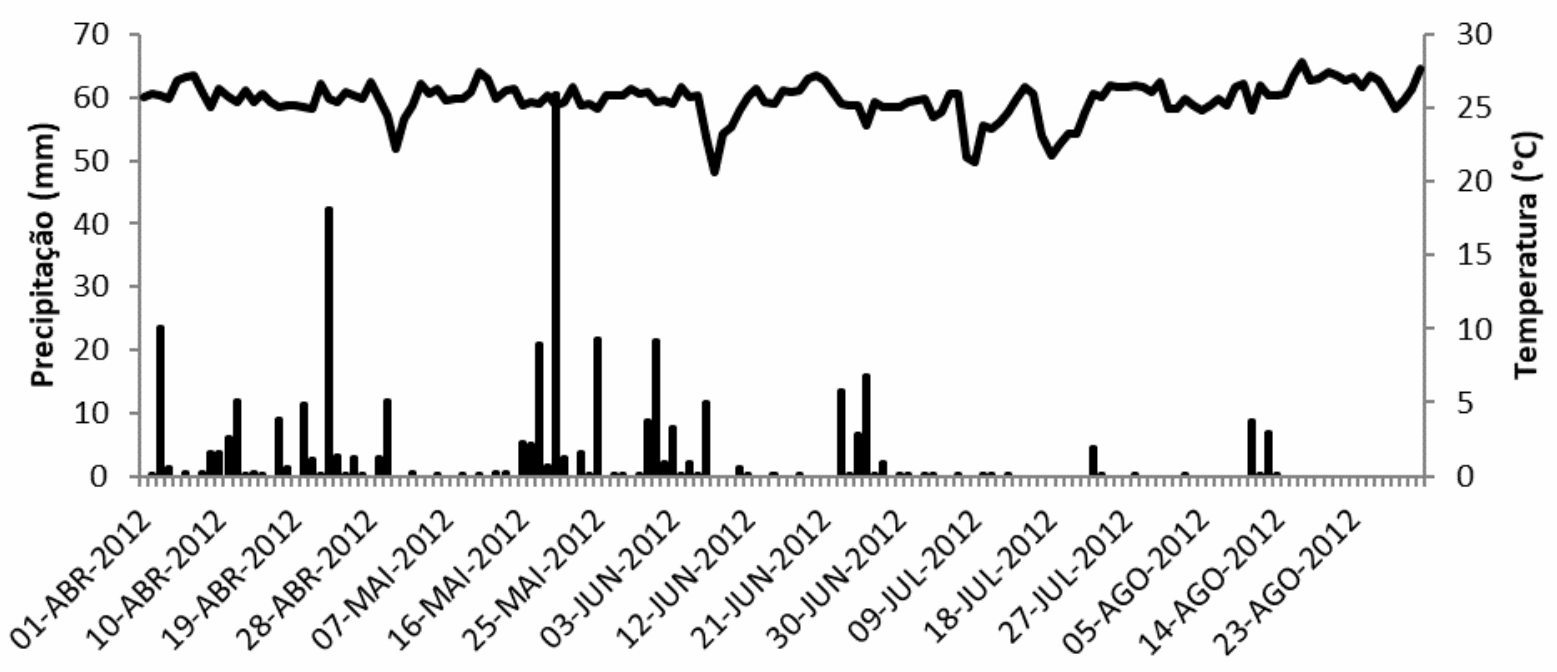

FIGURA 1. Precipitação pluviométrica e temperatura média do ar, registradas durante o experimento.

Fonte: INMET (2018)

O ensaio foi conduzido em área previamente cultivada com soja na safra. $\mathrm{O}$ preparo do solo foi realizado de maneira convencional por meio de duas gradagens, e posteriormente realizados os sulcos mecanicamente em um solo classificado como Latossolo Vermelho Amarelo distrófico, cujos atributos químicos, avaliados previamente à instalação do experimento são apresentados na Tabela 1.

TABELA 1. Atributos químicos da camada de 0 a $20 \mathrm{~cm}$ de profundidade de um Latossolo Vermelho Amarelo distrófico.

\begin{tabular}{|c|c|c|c|c|c|c|c|c|}
\hline $\mathrm{pH}$ & $\mathrm{P}$ & $\mathrm{K}$ & $\mathrm{Ca}$ & $\mathrm{Mg}$ & $\mathrm{H}+\mathrm{Al}$ & $\overline{\mathrm{Al}}$ & $\mathrm{MO}$ & $\mathrm{V}$ \\
\hline $\mathrm{H}_{2} \mathrm{O}$ & $\mathrm{mg} \mathrm{dm}^{-3}$ &.-- & $\cdots$ & $\mathrm{D}_{\mathrm{C}} \mathrm{dn}$ & --- & - & $\mathrm{g} \mathrm{kg}^{-1}$ & $\%$ \\
\hline 6,0 & 4,0 & 0,1 & 6,1 & 4,0 & 9,7 & 0.0 & 56,9 & 51 \\
\hline
\end{tabular}

$\mathrm{pH}$ em água 1:2,5, M.O. por digestão úmida, $\mathrm{P}$ e $\mathrm{K}$ determinados pelo método Mehlich I, Ca, Mg e Al trocáveis extraídos com $\mathrm{KCl} 1 \mathrm{~mol} \mathrm{~L}^{-1}$, $\mathrm{V}$ : saturação por bases.

Fonte: autores.

Seguiu-se o delineamento em blocos casualizados com 16 tratamentos (genótipos de milho) e quatro repetições. Cada parcela foi constituída por quatro linhas de $5,0 \mathrm{~m}$, espaçadas entre si em $0,90 \mathrm{~m}$, considerando como parcela útil as duas linhas centrais, desconsiderando-se $0,5 \mathrm{~m}$ de cada extremidade, a título de bordadura. Foram utilizados genótipos de milho de diferentes bases genéticas, ciclos e características agronômicas (Tabela 2). 
TABELA 2. Características agronômicas das cultivares de milho utilizadas para implantação do ensaio, na safrinha 2012.

\begin{tabular}{lcccc}
\hline Genótipos & Tipo* & Uso & Textura & Ciclo \\
\hline BRS 1040 & HS & G/SPI & SMDENT & SMP \\
BRS 1055 & HS & G/SPI & SMDENT & SMP \\
BRS 1060 & HS & G/SPI & SMDENT & SMP \\
1F640 & HSe & - & SMDURO & SP \\
2E530 & HDe & - & - & - \\
BRS Caimbé & $V$ & G/SPI & SMDURO & SMP \\
BRS 4103 & $V$ & Grãos & SMDURO & P \\
IAC 125 & Top cross & Pipoca & DURO & SP \\
IAC 8390 & HIV & G/SPI & SMDURO & N \\
Cativerde & $V$ & SPI/MV & DENT & SMP \\
AL Bandeirantes & $V$ & G/SPI & SMDURO & SMP \\
AL Avaré & $V$ & G/SPI & SMDURO & N \\
AL 34 & $V$ & G/SPI & SMDURO & SMP \\
AL Piratininga & $V$ & G/SPI/MV & SMDENT & SMP \\
30K75Y & HSm & Grãos & SMDURO & P \\
CD 384 HX & HT & Grãos & SMDURO & P \\
\hline
\end{tabular}

Tipo: HS - Híbrido simples; HSe - Híbrido simples experimental; V - variedade; HIV- Híbrido intervarietal; HSm - Híbrido simples modificado; HT - Híbrido triplo; HD - Híbrido duplo; HDe - Híbrido simples experimental. Uso: G - Grãos; SPI - Silagem da planta inteira; SGU - Silagem de grãos úmidos; MV - Milho verde. Textura do grão: SMDENT - Semidentado; SMDURO -Semiduro. Ciclo: SMP - Semiprecoce; SP - superprecoce; P - Precoce; N - Normal

Fonte: autores.

A semeadura foi realizada manualmente no dia 13/04/2012. A adubação de semeadura foi constituída de $300 \mathrm{~kg} \cdot \mathrm{ha}^{-1}$ do formulado 5-25-15. A adubação de cobertura foi realizada quando $50 \%$ das plantas apresentaram entre seis a oito folhas completamente expandidas, utilizando $100 \mathrm{~kg}^{-\mathrm{ha}^{-1}}$ do formulado 20-0-20. Quando necessário, os controles de plantas invasoras, pragas e doenças foram realizados conforme recomendações para a cultura.

Completada a maturação, foram coletados os dados das plantas na parcela útil e em seguida realizada a colheita manual das espigas para avaliação das variáveis. Foram avaliadas a altura de planta (da superfície do solo até a base da folha "bandeira"), altura de inserção de espiga (da superfície do solo ao ponto de inserção da espiga principal com o colmo), número de espigas doentes e estéreis, expresso em porcentagem, comprimento de espiga despalhada, diâmetro de espiga, massa de cem grãos e produtividade de grãos com massa corrigida para $13 \%$ de teor de água e resultados expressos em kg.ha-1.

Calculou-se a relação custo/benefício por meio do custo de produção do milho segunda safra, utilizando-se levantamento dos preços de insumos, operações e estrutura fixa na região de cerrado de Rondônia (Tabela 3). Avaliou-se somente os custos variáveis do milho segunda safra. O custo fixo remunera os fatores de produção, e as quantidades não são modificadas em curto prazo. Temos como custo fixo a conservação e juros sobre o capital empregado, a depreciação, custo alternativo da terra, máquinas, benfeitorias, equipamentos e mão-de-obra permanente. Essa rubrica representa a parte dos custos que o produtor assume, 
mesmo que os recursos não sejam totalmente utilizados. Atribuiu-se nesse trabalho, o custo fixo como inexistente, ou seja, esse foi totalmente alocado, remunerado pela cultura principal, a lavoura de soja em sucessão prévia ao milho.

O preço de equilíbrio (PE) determina o preço mínimo necessário a ser obtido para cobrir o custo de produção total considerando-se a produtividade média obtida pela cultivar (OLIVEIRA et al., 2015). É dado pela Equação 1.

Em que:

$$
P E=B / C
$$

$\mathrm{PE}=$ Preço de Equilíbrio

$\mathrm{B}=$ Custo Total de Produção, $\mathrm{R} \$$

$\mathrm{C}=$ Produtividade média obtida, $\mathrm{kg}$

TABELA 3. Custo de produção variável de milho cultivado em segunda safra ( $R \$$.ha ${ }^{1}$ ), em semeadura convencional, na região amazônica de Rondônia, 2012. Porto Velho, RO.

\section{Componentes do custo}

Custo Variável

\begin{tabular}{|c|c|c|c|c|}
\hline & Unidade & Quantidade & Unitário & Total \\
\hline \multicolumn{5}{|l|}{ Insumos } \\
\hline Sementes* & $\mathrm{kg}$ & 20 & Variável & Variável \\
\hline Fertilizante plantio (5-25-15) & $\mathrm{kg}$ & 300 & 1,43 & 429,00 \\
\hline \multicolumn{5}{|l|}{ Inseticida (Tiametoxam +Lambda- } \\
\hline $\begin{array}{l}\text { Cialotrina) ( } 2 \text { aplicações ) } \\
\text { Inseticida (Diflubenzurom) (2 }\end{array}$ & I & 0,5 & 90,00 & 45,00 \\
\hline aplicações) & I & 0,2 & 141,00 & 28,20 \\
\hline Herbicida (Atrazina) & I & 2,5 & 9,50 & 23,75 \\
\hline \multicolumn{5}{|l|}{ Preparo do solo e semeadura } \\
\hline Gradagem (2 operações) & $h m+i$ & 0,57 & 52,00 & 59,28 \\
\hline Plantio e adubação & $h m+i$ & 0,86 & 72,73 & 62,55 \\
\hline \multicolumn{5}{|l|}{ Tratos culturais } \\
\hline Mão-de-obra & $d \mathrm{~h}-1$ & 0,6 & 45,00 & 27,00 \\
\hline Aplicação de agrotóxicos (2 aplicações) & $h m+i$ & 0,62 & 99,00 & 61,38 \\
\hline Colheita & $\mathrm{hc}$ & 0,4 & 134,18 & 53,67 \\
\hline Recebimento e secagem* ${ }^{*}$ & saca & Variável & 1,00 & 70,00 \\
\hline Transporte externo* & saca & Variável & 0,40 & 30,00 \\
\hline Funrural $^{*}$ & $\begin{array}{l}2,30 \% \\
10,75 \%\end{array}$ & 0,023 & Variável & Variável \\
\hline Juros capital circulante (6 meses) & a.a & 0,054 & $1.010,83$ & 54,58 \\
\hline Total $^{*}$ & & & & Variável \\
\hline
\end{tabular}

$\mathrm{hm}+\mathrm{i}=$ hora máquina e implemento; $\mathrm{d} \mathrm{h}-1$ = dia homem; $\mathrm{hc}=$ hora colhedora .

* custos variáveis dependentes do genótipo avaliado e produtividade obtida pelo mesmo.

Fonte: os autores.

Os valores utilizados para os cálculos foram os vigentes na região norte de Rondônia em março (preços de insumos) e julho (preço de venda da saca de $60 \mathrm{~kg}$ ) de 2012. Preço médio do milho no mercado de Porto Velho para julho de 2012 foi de 
$\mathrm{R} \$ 20,00$ saca.ha $^{-1}$. Para o preço do milho pipoca, utilizou-se $80 \%$ do valor CEAGESP de julho de $2012\left(\mathrm{R} \$ 1,66 . \mathrm{kg}^{-1}\right)$ (AGRIANUAL, 2014). A receita líquida, refere-se à diferença entre a receita bruta obtida por parcela, pelo custo de produção específico de cada cultivar (custo varia devido ao preço diferenciado de semente entre variedades, de menor custo e híbridos, de maior custo e pelo custo de recebimento, secagem, transporte externo e Funrural, que dependem da produtividade de grãos). A relação custo/benefício, é calculada pela razão entre o custo de produção da parcela e a receita bruta, representado prejuízo da atividade para valores inferiores à 1 .

Os resultados obtidos foram submetidos à análise estatística utilizando o software SISVAR ${ }^{\circledR}$ e as médias das variáveis, quando significativas, comparadas pelo teste de médias Scott-Knott.

\section{RESULTADOS E DISCUSSÃO}

Todos os atributos agronômicos foram influenciados pelos genótipos $(p<0,05)$ (Tabela 4). $\mathrm{O}$ rendimento médio de grãos $\left(3.575 \mathrm{~kg}\right.$ ha $\left.{ }^{-1}\right)$ obtido foi inferior à média nacional do cultivo de milho segunda safra $\left(5.133 \mathrm{~kg}^{-h^{-1}}\right)(C O N A B, 2014)$. As baixas produtividades obtidas no experimento podem estar relacionadas às condições ambientais de baixas precipitações pluviais ocorridas durante as fases críticas do desenvolvimento da cultura (SOLER et al., 2007), visto que a semeadura do experimento ocorreu ao final do período de ocorrência de precipitações regulares (Figura 1). 
TABELA 4. Produtividade de grãos (PG), altura de inserção de espiga (Al), altura de planta (AP), comprimento de espiga (CE), diâmetro de espiga (DE), espigas doentes e estéreis (EDE), e massa de 100 grãos (MCG) de cultivares de milho cultivada no município de Porto Velho, Rondônia, na safrinha de 2012.

\begin{tabular}{|c|c|c|c|c|c|c|c|}
\hline Cultivares & PG (kg.ha $\left.{ }^{-1}\right)$ & $\mathrm{Al}(\mathrm{m})$ & $\operatorname{AP}(m)$ & CE (cm) & $\mathrm{DE}(\mathrm{cm})$ & EDE (\%) & MCG (g) \\
\hline $1 \mathrm{~F} 640$ & $5.424 \mathrm{a}$ & $1,00 \mathrm{~b}$ & $2,00 \mathrm{a}$ & $16,38 \mathrm{a}$ & $4,66 \mathrm{~b}$ & $9,00 \mathrm{c}$ & $27,50 \mathrm{~b}$ \\
\hline IAC 8390 & $4.723 \mathrm{~b}$ & $1,10 \mathrm{a}$ & $2,13 \mathrm{a}$ & $14,31 \mathrm{~b}$ & $4,48 \mathrm{c}$ & $19,66 \mathrm{c}$ & $27,40 \mathrm{~b}$ \\
\hline $30 \mathrm{~K} 75 \mathrm{Y}$ & $4.475 \mathrm{~b}$ & $1,00 \mathrm{~b}$ & $1,80 \mathrm{~b}$ & $17,01 \mathrm{a}$ & $4,36 \mathrm{c}$ & $10,00 \mathrm{c}$ & $30,31 \mathrm{a}$ \\
\hline 2E530 & $3.895 \mathrm{c}$ & $0,97 b$ & $1,97 b$ & 15,69 a & $4,30 \mathrm{c}$ & $19,00 \mathrm{c}$ & $28,21 b$ \\
\hline BRS 1060 & $3.874 \mathrm{c}$ & $0,80 \mathrm{~b}$ & $1,83 \mathrm{~b}$ & $14,79 \mathrm{~b}$ & $4,28 \mathrm{c}$ & $15,33 \mathrm{c}$ & $29,46 \mathrm{~b}$ \\
\hline BRS 4103 & $3.801 \mathrm{c}$ & $0,93 \mathrm{~b}$ & $1,97 \mathrm{~b}$ & $15,75 a$ & $4,78 \mathrm{a}$ & $33,66 \mathrm{~b}$ & $30,74 \mathrm{a}$ \\
\hline BRS Caimbé & $3.771 \mathrm{c}$ & $1,00 \mathrm{~b}$ & $2,03 \mathrm{a}$ & $16,54 \mathrm{a}$ & $4,84 \mathrm{a}$ & $14,66 \mathrm{c}$ & $32,47 \mathrm{a}$ \\
\hline AL Bandeirantes & $3.632 \mathrm{c}$ & $1,07 \mathrm{a}$ & $2,06 \mathrm{a}$ & 16,68 a & $4,59 \mathrm{~b}$ & $14,00 \mathrm{c}$ & $30,57 \mathrm{a}$ \\
\hline Cativerde & $3.352 d$ & $1,20 a$ & $2,17 \mathrm{a}$ & $14,59 \mathrm{~b}$ & $4,37 \mathrm{c}$ & $17,00 \mathrm{c}$ & $27,92 \mathrm{~b}$ \\
\hline AL Piratininga & $3.330 \mathrm{~d}$ & $0,93 \mathrm{~b}$ & $1,80 \mathrm{~b}$ & $14,93 \mathrm{~b}$ & $4,43 \mathrm{c}$ & $8,00 \mathrm{c}$ & $30,84 \mathrm{a}$ \\
\hline AL Avaré & $3.263 \mathrm{~d}$ & $0,97 \mathrm{~b}$ & $1,87 \mathrm{~b}$ & $15,22 b$ & $4,52 \mathrm{~b}$ & $13,00 \mathrm{c}$ & 29,89 a \\
\hline AL 34 & $3.164 \mathrm{~d}$ & $1,20 a$ & $2,30 \mathrm{a}$ & 16,22 a & $4,47 \mathrm{c}$ & $17,33 \mathrm{c}$ & $29,33 \mathrm{~b}$ \\
\hline CD $384 \mathrm{HX}$ & $3.098 d$ & $1,03 b$ & 1,77 b & $13,30 \mathrm{~b}$ & $4,36 \mathrm{c}$ & $27,66 \mathrm{~b}$ & $31,34 \mathrm{a}$ \\
\hline BRS 1055 & $2.912 \mathrm{~d}$ & $0,93 \mathrm{~b}$ & $2,10 \mathrm{a}$ & $14,80 \mathrm{~b}$ & $3,92 \mathrm{~d}$ & $21,66 \mathrm{c}$ & $27,89 \mathrm{~b}$ \\
\hline BRS 1040 & $2.701 \mathrm{~d}$ & $1,03 b$ & $2,10 \mathrm{a}$ & 13,22 b & $4,37 \mathrm{c}$ & $24,66 \mathrm{c}$ & $31,98 \mathrm{a}$ \\
\hline IAC 125 & $1.785 \mathrm{e}$ & $0,93 \mathrm{~b}$ & 1,83 b & 14,26 b & $2,95 \mathrm{e}$ & $45,33 \mathrm{a}$ & $13,04 \mathrm{c}$ \\
\hline CV (\%) & 16,02 & 8,39 & 6,1 & 6,5 & 3,27 & 35,38 & 4,6 \\
\hline Média geral & 3.575 & 1,01 & 1,98 & 15,2 & 4,35 & 19,37 & 28,68 \\
\hline
\end{tabular}

Médias seguidas de mesma letra, na coluna, não diferem entre si, pelo teste de Scott-Knott a $5 \%$ de probabilidade.

Fonte: os autores. 
A produtividade média do experimento $\left(3.575 \mathrm{~kg} \cdot \mathrm{ha}^{-1}\right)$ foi superior à obtida por outros autores, como Buso et al. (2017) avaliando diferentes genótipos de milho na segunda safra em experimento semeado dentro da época de semeadura recomendada (20 de fevereiro) localizado no município de Ceres em Goiás (1.911 kg.ha ${ }^{-1}$ ) e, Guimarães et al (2018) em estudo conduzido em Campo dos Goytacazes, Rio de Janeiro, demonstrando o potencial do cultivo de milho segunda safra, mesmo com semeaduras em períodos tardios, de maiores riscos, no fechamento da safrinha na região norte de Rondônia.

O híbrido de milho pipoca (IAC 125), obteve os menores índices de produtividade, com $1.785 \mathrm{~kg} \cdot \mathrm{ha}^{-1}$, correspondendo a $67,1 \%$ inferior $(\mathrm{p}<0,05)$ à maior obtida no experimento pelo uso do híbrido experimental 1F640 (5.424 kg.ha- ${ }^{-1}$ ). Quando se subtrai a média da cultivar IAC 125 da média geral, a produtividade média do experimento (3.694 kg.ha-1) foi superior à média obtida no estado de Rondônia para esta época, de $3.612 \mathrm{~kg} \cdot$ ha $^{-1}$ (CONAB, 2014).

Destaca-se o desempenho dos genótipos 1F640 e IAC 8390, que apresentaram rendimento de grãos superiores $(p<0,05)$ aos demais (Tabela 4). Observa-se que a cultivar IAC 125 obteve a menor produtividade, fato este que pode estar associado às características da mesma, na qual é destinada para a produção de milho pipoca. De maneira geral, as cultivares para milho pipoca são menos produtivas, quando comparadas às de produção de grãos (VIEIRA et al., 2016).

As produtividades obtidas nesse trabalho foram inferiores às obtidas por Rossato Júnior et al., (2013) na região norte de São Paulo e Silva et al (2015a) em Montividiu, Goiás semeadas na safra principal. Por outro lado, a produtividade média da cultivar IAC125 foi similar à produtividade obtida por Ávila et al., (2011), avaliando diversos genótipos de milho pipoca na região de Umuarama, Paraná no ano safra 2007/2008, cultivados sob diferentes lâminas e, nos estudos conduzidos por Scapim et al (2010) em Umuarama e Cidade Gaúcha, no estado do Paraná avaliando os genótipos (híbridos de linhagens, compostos e sintéticos).

O primeiro grupo, constituído pelo híbrido experimental 1F640 e o híbrido IAC 8390 proporcionaram incrementos médios de 33,6 e $62,8 \%$ sobre os demais grupos, exceto para a cultivar tipo pipoca, IAC 125, que teve uma diferença de $208 \%$ frente ao grupo mais produtivo. Este fato demonstra a importância da adequada escolha e posicionamento de cultivares, sejam híbridos ou variedades para o fechamento da safrinha na região norte doestado de Rondônia.

Dentre as cultivares mais produtivas, oito apresentaram produtividades superiores à média estadual na safra 2012: 1F640, IAC 8390, 30 K75Y, 2E530, BRS 1060, BRS 4103, BRS Caimbé e AL Bandeirantes. Por sua vez, o híbrido BRS1F640 revelou produtividades superiores à média nacional para o período. Haja vista a ausência de pesquisas na região, ressalta-se que épocas de semeadura mais precoces, e a utilização de espaçamentos variados e desta forma mais apropriados para cada genótipo, podem proporcionar patamares de produtividades superiores aos observados no presente trabalho (KAPPES et al., 2011).

Com relação à altura de inserção da espiga e altura de plantas observa-se uma divisão em dois grupos. A altura de inserção da espiga variou de 1,10 e 1,20 m, para o primeiro grupo e 0,80 a 1,03 m, para o segundo grupo. O primeiro grupo, com maiores alturas, foi composto apenas por variedades e híbrido intervarietal (IAC 8390, AL Bandeirantes, Cativerde e AL 34). A altura de plantas variou de 2,0 a 2,3m, para o primeiro grupo e 1,77 a $1,97 \mathrm{~m}$ para o segundo grupo. Pode-se observar que as variedades que compõem o primeiro grupo para altura de inserção de espigas 
estão inseridas no primeiro grupo de altura de plantas. Alves et al. (2016) não observaram correlação positiva entre estas duas variáveis, contudo, verificaram que a altura de inserção se correlaciona positivamente com o rendimento de grãos, dentre outras características morfológicas e nutricionais do milho.

Quanto ao comprimento de espigas, os genótipos que apresentaram os maiores comprimentos de espigas foram: 1F640, 30K75Y, BRS Caimbé, BRS 4103, AL Bandeirantes, 2E530 e AL 34. Observou-se uma variação de $28,7 \%(3,8 \mathrm{~cm})$ para essa variável entre os genótipos 30K75Y (17,0 cm) e o híbrido BRS 1040 (13,2 $\mathrm{cm})$. Valores considerados baixos, e que são inferiores aos reportados por Soares Neto et al. (2017) que encontraram no híbrido BM3061 um comprimento médio de 19,2cm e no AG1051 18,2 na região de Arapiraca, Alagoas ao testarem genótipos de milho especiais (verde) sob irrigação. Quanto ao diâmetro das espigas, os resultados foram considerados baixos, com uma média de $4,4 \mathrm{~cm}$; com diâmetros variando em $64 \%$, de $4,84 \mathrm{~cm}$ na variedade BRS Caimbé até o mínimo de 2,95 cm para a variedade pipoca IAC 125.

Observou-se que a cultivar IAC 125 apresentou a menor sanidade de espigas, com $45,3 \%$ das espigas doentes ou estéreis. Sendo um genótipo para produção de grãos pipoca, o que já lhe caracteriza como uma cultivar de baixa produtividade em relação às cultivares voltadas para a produção de grãos, a percentagem de espigas doentes e estéreis afetou diretamente os resultados de produtividade desta cultivar. Verificou-se uma variação de $37,3 \%$ entre as cultivares avaliadas para esse atributo, com valores variando entre $45,3 \%$ à $8 \%$ para a variedade AL Piratininga. Ressaltase que durante a condução do experimento, observou-se déficit hídrico durante fases críticas do desenvolvimento das cultivares, tal como durante o florescimento de algumas cultivares, o que pode ter propiciado falhas na formação de grãos nas espigas (MONTEIRO et al., 2017). Neste sentido, a utilização de combinação de cultivares e foco em genótipos precoces, em épocas de semeadura de safrinha, são preferíveis visando minimizar o risco de perdas por condições climáticas adversas (SILVA et al., 2015a).

Com relação à massa de cem grãos, destacou-se o desempenho das cultivares 30K75Y, BRS Caimbé, BRS 4103, AL Bandeirantes, AL Piratininga, CD $384 \mathrm{HX}$, AL Avaré e BRS 1040, que apresentaram as maiores massas, variando de 29,9 a 32,5 g. Já a cultivar IAC 125 apresentou o menor valor (13 g), o que auxilia a explicar a baixa produtividade obtida pelo híbrido.

Avaliando-se os resultados financeiros, observou-se que o custo de produção variou de $R \$ 1.684,09$ (IAC 125) à $R \$ 1.136,52$ (AL 34) por hectare (Tabela 5). Os menores custos de produção foram obtidos por meio do uso de variedades, devido ao menor custo de obtenção de sementes. Por outro lado, observa-se que a participação das sementes no custo total, foi baixo, variando de 1,78 à $0,3 \%$ do custo de produção total, demonstrando a baixa participação desse importante insumo no cômputo geral no custo da lavoura. Ressalta-se que o custo de produção foi influenciado, mesmo que tenuamente, pelos níveis de produtividade alcançados pelas diferentes cultivares, devido ao maior ou menor gasto com transporte externo, secagem e armazenamento dos grãos. 
TABELA 5. Relação benefício custo ( $B: C)$, receita líquida ( $R L)\left(R \$ h a^{-1}\right)$, receita bruta (RB) $\left(R \$\right.$ ha $\left.^{-1}\right)$ e custo de produção variável (CPV) $\left(R \$\right.$ ha $\left.^{-1}\right)$ por hectare de genótipos de milho para a região norte de Rondônia, entressafra 2012.

\begin{tabular}{lcccc}
\hline Genótipos & B:C & RL & RB & CPV \\
\hline IAC 125 & 2,65 & $2.778,62$ & $4.462,70$ & $1.684,09$ \\
IAC 8390 & 1,29 & 355,32 & $1.574,19$ & $1.218,87$ \\
1F640 & 1,23 & 334,35 & $1.808,08$ & $1.473,74$ \\
BRS 4103 & 1,10 & 114,38 & $1.266,93$ & $1.152,55$ \\
30K75Y & 1,08 & 106,51 & $1.491,66$ & $1.385,16$ \\
BRS Caimbé & 1,07 & 83,75 & $1.257,12$ & $1.173,38$ \\
AL Bandeirantes & 1,05 & 62,32 & $1.210,62$ & $1.148,30$ \\
2E530 & 0,99 & $-7,47$ & $1.298,41$ & $1.305,88$ \\
Cativerde & 0,98 & $-24,00$ & $1.117,25$ & $1.141,26$ \\
AL Piratininga & 0,97 & $-30,73$ & $1.109,98$ & $1.140,71$ \\
AL Avaré & 0,96 & $-51,30$ & $1.087,72$ & $1.139,02$ \\
AL 34 & 0,93 & $-82,01$ & $1.054,51$ & $1.136,52$ \\
BRS 1060 & 0,88 & $-186,38$ & $1.291,49$ & $1.307,39$ \\
CD 384HX & 0,78 & $-274,69$ & $1.032,70$ & $1.477,88$ \\
BRS 1055 & 0,69 & $-439,74$ & 970,80 & $1.410,54$ \\
BRS 1040 & 0,64 & $-504,76$ & 900,48 & $1.405,24$ \\
\hline Média geral & 1,08 & 139,63 & $1.433,41$ & $1.293,78$ \\
\hline Fon
\end{tabular}

Fonte: autores.

Os valores obtidos para o custo de produção foram condizentes aos verificados por Chieza et al. (2017) em sistemas de monocultivo na safra 2010/2011 na região de Seropédica, RJ e por Jasper et al. (2014), na região de Botucatú, SP, na safra de 2005/2006.

Apesar de apresentar os maiores custos de produção, devido ao maior custo de aquisição de sementes, e a menor produtividade de grãos, o híbrido IAC125 destacou-se no balanço econômico por apresentar a maior receita líquida ( $R$ \$ 2.778,62. ha ${ }^{-1}$ ) dentre os demais genótipos avaliados.

Somente os genótipos IAC 125, IAC 8390, BRS 1F640, BRS 4103, 30K75Y, BRS Caimbé e AL Bandeirantes apresentaram uma relação benefício custo superior à 1 , que representa uma receita líquida positiva necessária para a sustentabilidade econômica da atividade. Dentre esses materiais, três são variedade $(42,9 \%)$ e quatro são híbridos $(57,1 \%)$, demonstrando que o adequado posicionamento de genótipos não é dependente sempre e exclusivamente do tipo de sementes (híbridos ou variedade) e sim do genótipo em si.

Desconsiderando-se o híbrido IAC 125, que apresentou custo e preço de grãos diferenciados, na média, o preço de equilíbrio foi de $R \$ 20,59$ por saca, demonstrando que os preços da época ( $R \$ 20,00$ saca $\left.^{-1}\right)$ não remuneraram a atividade no geral. Ao se avaliar a cultivar IAC125, o preço de equilíbrio foi de $R \$$ 56,61 , considerado alto e que pode representar um alto risco à exploração dessa aptidão do híbrido de milho pipoca. 
A produtividade de equilíbrio média é dada pela razão entre o custo de produção e o preço do produto, e representa a produtividade mínima necessária a ser obtida para não haver prejuízo na atividade. No experimento, desconsiderando o híbrido IAC 125, a produtividade de equilíbrio foi de 63,4 sacas.ha $^{-1}$, ou $3.803,3$ $\mathrm{kg} \cdot \mathrm{ha}^{-1}$. Já para o híbrido pipoca, a produtividade de equilíbrio foi de apenas 16,9 sacas.ha ${ }^{-1}\left(1.014,5 \mathrm{~kg} \cdot \mathrm{ha}^{-1}\right)$.

\section{CONCLUSÕES}

Os genótipos 1F640 e IAC 8390 apresentaram as maiores produtividades de grãos com médias de 5.474 e $4.977 \mathrm{~kg}$ ha $^{-1}$, respectivamente.

No geral, as variedades apresentaram menores custos de produção, contudo, o menor custo não reflete necessariamente em maior relação benefício custo, que foi obtida por híbridos.

A cultivar de milho pipoca (IAC 125) apresentou os maiores custos de produção e menor produtividade de grãos, o que representou maior receita líquida entre os genótipos avaliados.

\section{REFERÊNCIAS}

AGRIANUAL - Anuário da Agricultura Brasileira. São Paulo: Instituto FNP, 2014, $374 p$.

ALVES, B. M.; FILHO, A. C.; BURIN, C.; TOEBE, M. Correlações canônicas entre caracteres agronômicos e nutricionais proteicos e energéticos em genótipos de milho. Revista Brasileira de Milho e Sorgo, v. 15, n.2, p. 171-185, 2016. Disponível em: $\quad<$ https://doi.org/10.18512/1980-6477/rbms.v15n2p171-185>. doi: 10.18512/1980-6477/rbms.v15n2p171-185

ÁVILA, M. R.; GOMES, E. P.; FEDRI, G.; SCAPIM, C. A.; BARIZÃO, D. A. O.; ALBRECHT, L. P.; RODOVALHO, M. A. Híbridos de milho pipoca cultivados sob diferentes lâminas de irrigação. Scientia Agraria, Curitiba, v.12, n.4, p.199-209, Jul./Dez 2011. Disponível em:

https://revistas.ufpr.br/agraria/article/view/40825/24962

BASTOS, T.X.; DINIZ, T.D. de A.S. Avaliação de clima do Estado de Rondônia para desenvolvimento agrícola. Belém: EMBRAPA/CPATU, 1982. 28p. (Boletim de Pesquisa, 44). Disponível em: https://www.embrapa.br/busca-de-publicacoes//publicacao/381150/avaliacao-do-clima-do-estado-de-rondonia-paradesenvolvimento-agricola

BUSO, W. H. D.; SILVA, L. B.; SILVA, S. M. C.; LEÃO JÚNIOR, L. A. Desempenho agronômico de híbridos de milho em três épocas de semeadura no cerrado goiano. Revista de Agricultura Neotropical, Cassilândia-MS, v. 4, n. 4, p. 46-52, out./dez. 2017. Disponível em:

https://periodicosonline.uems.br/index.php/agrineo/article/view/1826

CARVALHO, E. V.; AFFÉRRI, F. S.; PELÚZIO, J. M.; ROTILI, E. A.; DOTTO, M. A.; SANTOS, W. F. Estratificação e dissimilaridade ambiental em genótipos de milho no Tocantins, com adubação e safras distintas. Comunicata Scientiae, v. 4, n. 3, p. 277-284, 2013. 
$<$ https://comunicatascientiae.com.br/index/search/authors/view?firstName=Weder\&m iddleName=Ferreira\&lastName=dos\%20Santos\&affiliation=UFT\&country=>

CHIEZA. E. D.; GUERRA, J. G. M.; ARAÚJO, E. S.; ESPÍNDOLA, J. A.; FERNANDES, R. C. Produção e aspectos econômicos de milho consorciado com Crotalária juncea L. em diferentes intervalos de semeadura, sob manejo orgânico. Revista Ceres, v. 64, n. 2, p. 189-196, 2017. <http://dx.doi.org/10.1590/0034737×201764020012>. doi: 10.1590/0034-737x201764020012

CONAB - Companhia Nacional de Abastecimento. Acompanhamento de safra Brasileira: Grãos, Safra 2013/2014, décimo primeiro levantamento da safra $n^{\circ} 11$, ago, 2014. Disponível em:

<http://www.conab.gov.br/OlalaCMS/uploads/arquivos/14_08_07_08_59_54_boletim _graos_agosto_2014.pdf>

CONAB - Companhia Nacional de Abastecimento. Acompanhamento da safra de grãos. Acompompanhamento da safra brasileira de grãos, v. 5 Safra 2017/18 Quinto levantamento, Brasília, p. 1-140 fevereiro 2018. Disponível em: http://www.ampa.com.br/arquivos/conab/08022018094316.pdf. Acesso em: 20 de outubro de 2018

FALEIROS, G. D.; SANTOS, D. F. L.; CORÁ, J. E. Analysis of profitability of conservation tillage for a soybean monoculture associated with corn as an off-season crop. Cogent Food \& Agriculture, v. 4, n. 1, 2018. Disponível em: <https://doi.org/10.1080/23311932.2018.1429699>. doi: $10.1080 / 23311932.2018 .1429699$

GUIMARÃES, A. G.; AMARAL JÚNIOR, A. T.; LIMA, V. J.; LEITE, J. T.; SCAPIM, C. A.; VIVAS, M. Genetic gains and selection advances of the UENF -14 popcorn population. Revista Caatinga, Mossoró, v. 31, n. 2, p. 271-278, abr.-jun., 2018. Disponível em: https://periodicos.ufersa.edu.br/index.php/caatinga

JASPER, S. P.; VELINI, E. D.; SOUZA, S. F. G. Comparação econômica do milho produzido com efeito hormético. Revista Agrarian, v. 24, n. 2, p. 348-354, 2014. Disponível em: <http://ojs.ufgd.edu.br/index.php/agrarian/article/view/2242/1812>

INSTITUTO NACIONAL DE METEOROLOGIA (INMET). Gráficos Climatológicos. Brasília: INMET, 2018. Disponível em:

http://www.inmet.gov.br/portal/index.php?r=clima/graficosClimaticos. Acesso em: outubro de 2018

KAPPES, C.; ANDRADE J. A. C.; ARF, O.; OlIVEIRA, A. C.; ARF, M. V.; FERREIRA, J. P. Desempenho de híbridos de milho em diferentes arranjos espaciais de plantas. Bragantia, v. 2, n. 4, p. 334-343, 2011. Disponível em: http://dx.doi.org/10.1590/S0006-87052011000200012. doi: 10.1590/S000687052011000200012 
MONTEIRO, J. E. B. A.; ASSAD, E. D.; SENTELHAS, P. C.; COSTA AZEVEDO, L. Modeling of corn yield in Brazil as a function of meteorological conditions and technological level. Pesquisa Agropecuária Brasileira, v. 52, n. 3, p. 137-148. 2017 <https://doi.org/10.1590/S0100-204X2017000300001>. doi: 10.1590/S0100204X2017000300001

OLIVEIRA, C. O.; LAZARINI, E.; TARSITANO, M. A. A.; PINTO, C. C.; SÁ, M. E. Custo e lucratividade da produção de sementes de soja enriquecidas com molibdênio. Pesquisa Agropecuária Tropical, Goiânia, v. 45, n. 1, p. 82-88, jan./mar. $\quad 2015 . \quad \quad$ http://dx.doi.org/10.1590/1983-40632015v4527961>. doi.org/10.1590/1983-40632015v4527961

OLIVEIRA, I. Jr.; ATROCH, A. L., DIAS, M. C.; GUIMARÃES, L. J.; GUIMARÃES, P. E. O. Seleção de cultivares de milho quanto à produtividade, estabilidade e adaptabilidade no Amazonas. Pesquisa Agropecuária Brasileira, Brasília, v.52, n.6, p.455-463, jun. 2017. <http://dx.doi.org/doi: 10.1590/S0100204X2017000600009>. doi: 10.1590/S0100-204X2017000600009

ROSSATO JUNIOR, J. A. D. S.; CAZETTA, D. A.; BARBOSA, J. C.; FORNASIERI FILHO, D. Popping expansion and yield responses of popcorn cultivars under different row spacings and plant populations. Pesquisa Agropecuária Brasileira, v.48, n.12, p.1538-1545, 2013. <http://dx.doi.org/10.1590/S0100204X2013001200002>. doi: 10.1590/S0100-204X2013001200002

SANTOS, W. F.; AFFÉRRI, F. S.; PELÚZIO, J. M.; SODRÉ, L. F.; ROTILI, E. A.; CERQUEIRA, F. B.; FERREIRA, T. P. Genetic diversity in maize under nitrogen restriction conditions. Journal of Bioenergy and Food Science, v. 5, n. 2, p. 44-53, 2018. <https://doi.org/10.18067/jbfs.v5i2.190>. doi: 10.18067/jbfs.v5i2.190

SCAPIM, C. A.; Amaral Júnior, A. T.; VIEIRA, R. A.; Moterle, L. M.; TEXEIRA, L. R.; VIGANÓ, J.; SANDOVAL JÚNIOR, G. B. Novos compostos de milho-pipoca para o Brasil. Semina: Ciências Agrárias, Londrina, v. 31, n. 2, p. 321-330, abr.jun. 2010. Disponível em: http://www.redalyc.org/html/4457/445744096005/

SILVA, A. G.; FRANCISCHINI, R.; MARTINS, P. D. S. Desempenhos agronômico e econômico de cultivares de milho na safrinha. Revista Agrarian, v. 8, p. 1-11, 2015a.

Disponível

em:

<http://ojs.ufgd.edu.br/index.php/agrarian/article/view/2347/2166>

SILVA, G. C.; SCHMITZ, R.; SILVA, L. C.; CARPANINI, G. G.; MAGALHÃES, R. C. Desempenho de cultivares para produção de milho verde na agricultura familiar do sul de Roraima. Revista Brasileira de Milho e Sorgo, v.14, n.2, p. 273-282, $2015 \mathrm{~b}$. <http://dx.doi.org/10.18512/1980-6477/rbms.v14n2p273-282> doi.org/10.18512/1980-6477

SOARES NETO, J. C.; SANTOS NETO, A. L.; SANTOS, W. M.; BARROS, D. T. S.; SOUZA, A. A.; ALBUQUERQUE NETO, J. C. Performance of irrigated green corn cultivars in different plant populations at sowing. Revista Brasileira de Engenharia Agrícola e Ambiental, v. 21, n. 4, p. 267-272, 2017. 
$<$ https://dx.doi.org/10.1590/1807-1929/agriambi.v21n4p267-272>. doi: 10.1590/18071929/agriambi.v21n4p267-272

SOLER, C. M. T.; HOOGENBOOM, G., SENTELHAS, C. DUARTE, A. P. Impact of Water Stress on Maize Grown Off-Season in a Subtropical Environment. Journal of Agronomy and Crop Science, v. 193, p. 247-261, 2007. Disponível em: <https://doi.org/10.1111/j.1439-037X.2007.00265.x>. doi: 10.1111/j.1439037X.2007.00265.X

SUZUKAWA, A. K.; PEREIRA, C. B.; GARCIA, M. M.; SOTO, R. I. C.; ZEFFA, D. M.; COAN, M. M. D.; SCAPIM, C. A. Diallel analysis of tropical and temperate sweet and supersweet corn inbred lines. Revista Ciência Agronômica, v. 49, p. 607, 2018. Disponível em: <http://ccarevista.ufc.br/seer/index.php/ccarevista/article/view/5620/1759>

VIEIRA, R. A.; ROCHA, R.; SCAPIM, C. A.; AMARAL JÚNIOR, A. T.; VIVAS, M. Selection index based on the relative importance of traits and possibilities in breeding popcorn. Genetics and Molecular Research, v. 15, n. 2, 2016. Disponível em: <https://doi.org/10.4238/gmr.15027719>. doi: 10.4238/gmr.15027719 